\title{
INFLUENCING FACTORS AND MECHANISM ON THE SAFETY INTEGRITY OF AIRLINE EMPLOYEES
}

\author{
LI LI $^{1,2}$, JIU-LONG CHENG ${ }^{3} \&$ JUE CHANG ${ }^{4}$ \\ ${ }^{1}$ School of Resources and Safety Engineering, China University of Mining and Technology(Beijing),China. \\ ${ }^{2}$ Flight Technology College, Civil Aviation University of China, China. \\ ${ }^{3}$ School of Geoscience and Surveying Engineering, China University of Mining and Technology(Beijing), China. \\ ${ }^{4}$ China Express Airlines, China.
}

\begin{abstract}
Introduction: With the rapid development of the civil aviation industry and the growth in the number of airline employees, some unsafe and dishonest events occur frequently. These behaviors affect the flight safety seriously. Method: First of all, the connotation of safety integrity was defined based on literature analysis. According to the connotation, relevant typical cases were collected. Through the use of Field Theory for case analysis, the main factors that affect safety integrity were identified. By using DEMATEL-G1 and DEMATEL-ISM methods, the relationships between these factors were analyzed quantitatively, and the internal effect paths of the influencing factors were established. Results: There are sixteen major factors that affect the safety integrity of airline employees. Six of them are crucial. The effect path system of all factors can be divided into four layers: the first layer is the appearance layer, including eight factors, which are the direct causes affecting airline employee's safety integrity; the second layer is the middle layer; the third and the fourth layers are the root layers, including four factors, which are the deep causes affecting airline employee's safety integrity. It is also worth noticing that "incentive and penalty system of safety integrity", "supervision of government and company"," stability and efficiency of the organization", "emphasis and example of leaders on safety integrity" are not only crucial factors, but also the root layers of the structural model. They are the most important factors.

Keywords: airline employees, case analysis, DEMATEL-G1, DEMATEL-ISM, Field Theory, hierarchical structure model, influencing factors, safety integrity
\end{abstract}

\section{INTRODUCTION}

With the development of the global economy and the opening of civil aviation market, the global aviation industry continues to develop at a relatively rapid speed. Based on the statistics provided by Flight Global [1], airlines delivered 1704 aircrafts in 2016. Compared with 2015 , the amount of shipments have a $2 \%$ increase. It marks the sixth consecutive year of increased deliveries. With the increasing growth of fleet size and the rapid growth of the number of airline employees, some unsafe and dishonest events occur frequently. In order to avoid taking responsibility, somebody provided false information to interfere with the normal investigation procedures in an accident investigation. In order to obtain a career development space, somebody forged or altered documents, which could prove his experience, in applying for a flight license. In order to maximize profits, somebody lied about the amount of fuel on board to get a priority landing. The dishonest behaviors, not only affect flight safety, but also disturb the normal operation order of civil aviation and cause a bad effect on both inside and outside civil aviation. Today, there are many research findings related to integrity. Those related findings mainly focus on the psychological structure of individual integrity [2-4], the measurement of integrity [5-7] the integrity of education and academia [8, 9], etc. However, academic researches on the safety integrity of airline employees are few. 
This paper aims to investigate the influencing factors and their internal mechanism on the safety integrity of airline employees. First of all, the connotation of safety integrity was defined on the basis of literature analysis, and the relevant typical cases were collected according to it. And then the cases were analyzed based on the Field Theory so that influencing factors were identified. Decision Making Trial and Evaluation Laboratory (DEMATEL) was used to calculate the causal degree and the central degree of influence factors. Ordinal Relation Analysis (G1) is used to correct the central degree, the important degree of factors are quantified scientifically. On this basis, Interpretive Structural Modeling (ISM) is introduced to construct the hierarchical structure model of influencing factors, which further reveals the internal level and the mechanism of factors. Hopefully, the results of research can provide theoretical support for airlines as well as the civil aviation authorities to improve the status of safety integrity effectively.

\section{DETERMINATION OF INFLUENCING FACTORS ON AIRLINE EMPLOYEE'S SAFETY INTEGRITY}

\subsection{Safety integrity connotation}

It is widely believed that integrity is of vital importance, which is usually discussed in some related research. "Integrity" stems from the Latin word "integrita", which means completeness or wholeness. When applied to behavior, integrity describes a person who completely or wholly possesses "soundness of moral principle; character of uncorrupted virtue; and uprightness, honesty, sincerity" [10]. On the basis of this meaning, scholars [11] further put forward that "integrity" was considered to consist of three different but interrelated dimensions: the quality or state of being complete; the entire, unimpaired or perfect state or quality of anything; and the quality or state of being of sound moral principle. In psychology, integrity, as a kind of moral norms, is often understood as honest and trustworthy. It includes three meanings, that is, delivering what we promise, following acts and regulations, and maintaining an honest and open dialogue [12]. Palanski and Yammarino [13] divided integrity clustering into five groups: authenticity, wholeness, deeds accord with words, consistency in the face of adversity, and ethics and morality.

At present, the research of safety integrity is mainly focused on the coal, shipping, food, and power industry. Cheng and $\mathrm{Gu}$ [14] proposed that safety integrity includes three dimensional constructs: whether the manager has a strong safety consciousness; whether the enterprise is actively fulfilling safety responsibilities and obligations; whether the enterprise has the ability to keep safety integrity. On the other hand, Ji and Li [15] argued that safety integrity for enterprises and individuals meant complying with the relevant laws and regulations strictly, fulfilling responsibilities of posts, performing the safety commitment and maintaining the good working style. Also, Cheng et al. [16] considered that safety integrity for employees is a comprehensive ability, which includes the strong safety awareness in the production, compliance with laws and regulations and a strong ability of emergency rescue.

Combined with the characteristics of airline work, according to the above literature analysis, the connotation of airline employee's safety integrity can be concluded. Employees have strong safety awareness in their work, comply with laws and regulations, fulfill safety responsibilities and obligations, keep their safety promises, seek the truth from facts, and guarantee safety in production. 


\subsection{Determination of influencing factors based on case analysis}

Unsafe events, which have occurred, exposed the safety risks of the system. Analysis of statistics based on historical data is an important way to explore the influencing factors and internal regulations. Therefore, this study reviewed 108 survey reports of "worlds' civil aviation accident investigation" [17] from 2011 to 2016. These reports recorded 694 civil aviation accidents, incidents and unsafe events in the world during 2008 to 2016. Based on the connotation of safety integrity, 71 cases were selected from 694 cases. In addition, 15 typical cases of violating safety integrity in China were also collected. The total number of the selected cases is 86.

Psychological Field Theory was developed by K. Lewin [18] in the 1940s, which examines patterns of interactions between person and environment. Field Theory can be expressed by a formula: $\mathrm{B}=\mathrm{f}(\mathrm{p}, \mathrm{e}) . \mathrm{B}$ means that a person's behavior, which depends on the interactions between the personal internal factors (p) and his/her environment (e). The internal factors include not only the psychological and physiological characteristics, but also the individual characteristics. The external environment includes natural environment and social environment. The two factors interact and influence each other. Field Theory can be used to analyze the influencing factors of the unsafe integrity behavior of airline employees. 86 unsafe integrity events were analyzed by the Field Theory, and 34 influencing factors were identified. As shown in Table 1, the similar influencing factors were integrated and 16 influencing factors were derived.

Many scholars have done some research on the factors affecting (safety) integrity. Based on a series of studies about dishonest behaviors in distance higher education institutions, Farisi [8] offered that individual, society, culture, and institutions are factors that play

Table 1: Summary of influencing factors on the safety integrity of airline employees.

\begin{tabular}{ll}
\hline Influence factors & Number \\
\hline Individual professional knowledge and skills & $\mathrm{S}_{1}$ \\
Individual awareness of safety integrity & $\mathrm{S}_{2}$ \\
Individual physical condition & $\mathrm{S}_{3}$ \\
Individual psychological state & $\mathrm{S}_{4}$ \\
Facilities of air traffic control department and airport & $\mathrm{S}_{5}$ \\
Social and industrial currents & $\mathrm{S}_{6}$ \\
Incentive and penalty system of safety integrity & $\mathrm{S}_{7}$ \\
Communication and coordination among airlines, airport and air traffic control & $\mathrm{S}_{8}$ \\
department & \\
Supervision of government and company & $\mathrm{S}_{9}$ \\
Related education, propaganda and safety cultural atmosphere & $\mathrm{S}_{10}$ \\
Stability and efficiency of the organization & $\mathrm{S}_{11}$ \\
Standardization of guidance documentation & $\mathrm{S}_{12}$ \\
Emphasis and example of leaders on safety integrity & $\mathrm{S}_{13}$ \\
Management of organizational resource & $\mathrm{S}_{14}$ \\
Safety input & $\mathrm{S}_{15}$ \\
Establishment of the company management system and division of job & $\mathrm{S}_{16}$ \\
responsibilities & \\
\hline
\end{tabular}


significant roles in the emergence of dishonest behavior. Ones et al. [3] pointed out that the dimension of responsibility in the big five personality models is most relevant to the integrity. And the leader's integrity was the source of the organization's ethical atmosphere [19-21]. Grover [22] believed that lacking of capabilities and resources can cause lying while improper allocation of resources can also lead to employees' dishonesty. Researchers [23, 24] also found that organizations with dishonest culture will have employees who are more likely to engage in dishonesty. And culture can also be emphasized by reward and penalty systems, and organizations that impose financial penalties may also create a culture which creates the possibility of dishonesty [25].The results of the above studies are consistent with the analysis results in Table 1.

\section{RELATIONSHIP OF INFLUENCING FACTORS ON AIRLINE EMPLOYEE'S SAFETY INTEGRITY}

DEMATEL is based on graph theory and matrix tools, proposed by Fontela and Gabus [26]. It requires the experts to assign the direct influence relationship among factors, and construct the direct influence matrix. The central degree and the causal degree of factors can be calculated, and the main factors in complex systems can be filtered out. However, experts only consider the direct relationship between influence factors in assigning values to the direct influence matrix, without considering the influence of each factor on the target. G1 is an improved weight assignment method based on analytic hierarchy process, proposed by Guo, Y.J. and Wang, X.J. [27, 28]. It considers chiefly the effects of each factor on the target, discarding the effects of the factors. And it has the characteristics of no consistency test. G1 method was used to correct the center calculation obtained by DEMATEL in this paper, which made the center degree more scientific.

\subsection{Generating the direct relationship matrix}

The factors affecting the safety integrity of airline employees have been determined according to previous analysis, and they were denoted as $s_{1}, s_{2}, s_{3} \ldots s_{n}$ (see Table 1). Based on the expert's decision, the direct influencing degree between factors was determined, and the direct influence matrix $X$ was constructed.

20 experts were invited to analyze the direct effect relationships of 16 factors in this study. Among them, 10 experts are scholars engaged in long-term research related to the safety integrity of civil aviation, 5 are senior staff members of the Civil Aviation Authority who have long been engaged in civil aviation safety management, and 5 are senior staff engaged in airline safety management. 0 represents no direct impact; 1 represents slight impact; 2 represents moderate impact; 3 represents high impact. The direct influence matrix of airline employee's safety integrity was constructed.

\subsection{Constructing the comprehensive influence matrix}

The direct relationship matri $X$ was normalized to form normalized direct relationship matrix $G$ as eqn (1). And the comprehensive influence matrix $T$ was defined as eqn (2).

$$
G=\frac{1}{\operatorname{Max}_{1 \leq i \leq n}\left(\sum_{j=1}^{n} x_{i j}\right)} X
$$




$$
T=\lim _{m \rightarrow \infty}\left(G+G^{2}+\cdots+G^{m}\right)=G(I-G)^{-1}
$$

The comprehensive influence matrix of influencing factors on airline employees' safety integrity was constructed as following:

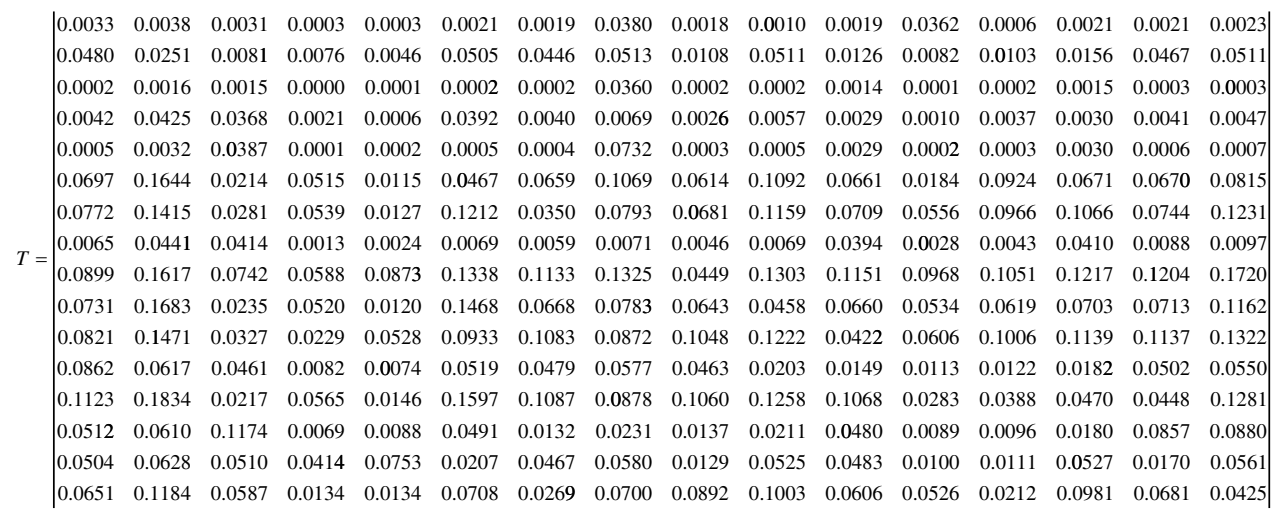

\subsection{Calculation of the causal degree and central degree of each factor}

The influencing degree of each factor is the sum of the elements in the comprehensive influence matrix, $f_{i}=\sum_{j=1}^{16} t_{i, j}(i=1,2, \cdots, n)$.The affected degree of each factor is the sum of the columns in the comprehensive influence matrix, $e_{i}=\sum_{j=1}^{16} t_{\mathrm{j}, \mathrm{i}}(i=1,2, \cdots, n)$. Here $t$ is the element in the composite influence matrix $T$.The formula for calculating the central degree is $m_{i}=f_{i}+e_{i}$. The formula for calculating the causal degree is $n_{i}=f_{i}-e_{i}$. Through the central degree, we can examine the importance of the factor $s_{i}$ in the system. Through the positive and negative of the causal degree, it can be judged whether the factor is the causal or the resulting factor.

\subsection{Calculation of weight coefficient based on G1 method}

\subsubsection{Determining order relations}

Supposing that $x_{1}, x_{2}, \cdots, x_{n}$ are indexes, they are treated by index type consistency and non-dimensional processing.

Define If the contribution of the index $x_{i}$ to the evaluation target is not inferior to $x_{j}$, it is denoted as $x_{i} \geq x_{j}$.

Define If the indexes $x_{1}, x_{2}, \cdots, x_{n}$ have the relation $x_{1}^{*} \geq x_{2}^{*} \geq \cdots \geq x_{n}^{*}$, It is considered that the evaluation indexes have established the order relationship.

Here, $x_{i}^{*}$ means it is the $i$ evaluation index of $\left\{x_{i}\right\}$ after ordinal arrangement. $(i=1,2, \cdots, n)$

According to the expert's decision, order relation is given to 16 influencing factors. The results are as follows:

$$
x_{2} \geq x_{10} \geq x_{7} \geq x_{13} \geq x_{9} \geq x_{6} \geq x_{1} \geq x_{12} \geq x_{16} \geq x_{11} \geq x_{14} \geq x_{4} \geq x_{3} \geq x_{15} \geq x_{8} \geq x_{5}
$$


3.4.2 Calculation of weight coefficient $w_{k}$
It is assumed that the ratio between the index $x_{k-1}^{*}$ and $x_{k}^{*}$ is $r_{k}^{*}=w_{k-1}^{*} / w_{k}^{*}(k=2,3 \cdots n)$. According to the ratio of the importance of $x_{k-1}^{*}$ to $x_{k}^{*}$, the range of $r_{k}^{*}$ is $\{1.0,1.2,1.4,1.6,1.8\} .1 .0$ represents $x_{k-1}^{*}$ is as important as $x_{k}^{*}, 1.2$ represents $x_{k-1}^{*}$ is a little more important than $x_{k}^{*}$, and so on. If the expert gives the index $r_{k}^{*}$ assignment, $w_{k}^{*}$ is:

$$
w_{k}^{*}=\left(1+\sum_{k=2}^{n} \prod_{i=k}^{n} r_{i}^{*}\right)^{-1}
$$

The weight of the evaluation index $x_{i}^{*}$ is:

$$
w_{i}^{*}=\left(\begin{array}{l}
0.1616,0.1155,0.0962,0.0802,0.0802,0.0668,0.0557,0.0464 \\
0.0464,0.0464,0.0464,0.0386,0.0386,0.0322,0.0268,0.0224
\end{array}\right)
$$

Corresponding to the index $x_{i}^{*}$, the importance weight of index $x_{i}$ is

$$
w_{i}=\left(\begin{array}{l}
0.0557,0.1616,0.0386,0.0386,0.0224,0.0668,0.0962,0.0286 \\
0.0802,0.1155,0.0464,0.0464,0.0802,0.0464,, 0.0322,, 0.0464
\end{array}\right)
$$

\subsection{Calculation of the important degree}

The method of combining weights is used to optimize the center weight. Combining weights are usually use these two ways: the addition and the multiplication. In order to highlight the importance of differences between indexes, the multiplicative combination was selected here ( see eqn (4)).

$$
M_{i}^{\prime}=\frac{m_{i} w_{i}}{\sum_{i=1}^{n} m_{i} w_{i}}(i=1,2, \cdots n)
$$

The central degree is combined with the weights obtained by G1 to obtain the corrected centrality, which namely important degree. The results of data processing are shown in Table 2 and Fig. 1.

\section{HIERARCHICAL STRUCTURE OF INFLUENCING FACTORS ON AIRLINE EMPLOYEE'S SAFETY INTEGRITY}

Through the previous analysis, we have quantified the relationship between factors. Then, the hierarchical structure model of these influencing factors will be constructed. ISM was proposed by Warfield, J. [29]. Both DEMATEL and ISM are based on graph theory and matrix theory. Non-zero elements of comprehensive influence matrix of DEMATEL and accessible matrix of ISM represent the interaction between indicators. Zero elements represent no influence relationship between indicators. In addition, the computation of the comprehensive influence matrix is less than the reachable matrix [30]. Therefore, in order to simplify the calculation process, the comprehensive influence matrix of DEMATEL can replace the reachable matrix of ISM. 
Table 2: Relationship of influencing factors on airline employee's safety integrity.

\begin{tabular}{|c|c|c|c|c|c|c|c|}
\hline $\begin{array}{l}\text { Influencing } \\
\text { factors }\end{array}$ & $\begin{array}{l}\text { Influencing } \\
\text { degree }\end{array}$ & $\begin{array}{l}\text { Affected } \\
\text { degree }\end{array}$ & $\begin{array}{l}\text { Causal } \\
\text { degree }\end{array}$ & $\begin{array}{l}\text { Central } \\
\text { degree }\end{array}$ & $\begin{array}{l}\text { Weight } \\
\text { coefficient }\end{array}$ & $\begin{array}{l}\text { Important } \\
\text { degree }\end{array}$ & $\begin{array}{l}\text { Factor } \\
\text { attribute }\end{array}$ \\
\hline$s_{1}$ & 0.1008 & 0.8199 & -0.7191 & 0.9207 & 0.0557 & 0.0301 & $\begin{array}{l}\text { Resulting } \\
\text { factor }\end{array}$ \\
\hline$s_{2}$ & 0.4462 & 1.3906 & -0.9444 & 1.8368 & 0.1616 & 0.1742 & $\begin{array}{l}\text { Resulting } \\
\text { factor }\end{array}$ \\
\hline$s_{3}$ & 0.0440 & 0.6044 & -0.5604 & 0.6484 & 0.0386 & 0.0147 & $\begin{array}{l}\text { Resulting } \\
\text { factor }\end{array}$ \\
\hline$s_{4}$ & 0.1640 & 0.3769 & -0.2129 & 0.5409 & 0.0386 & 0.0123 & $\begin{array}{l}\text { Resulting } \\
\text { factor }\end{array}$ \\
\hline$S_{5}$ & 0.1253 & 0.3040 & -0.1787 & 0.4293 & 0.0224 & 0.0056 & $\begin{array}{l}\text { Resulting } \\
\text { factor }\end{array}$ \\
\hline$s_{6}$ & 1.1011 & 0.9934 & 0.1077 & 2.0945 & 0.0668 & 0.0821 & Causal factor \\
\hline$s_{7}$ & 1.2601 & 0.6897 & 0.5704 & 1.9498 & 0.0962 & 0.1101 & Causal factor \\
\hline$s_{8}$ & 0.2331 & 0.9933 & -0.7602 & 1.2264 & 0.0268 & 0.0193 & $\begin{array}{l}\text { Resulting } \\
\text { factor }\end{array}$ \\
\hline$s_{9}$ & 1.7578 & 0.6319 & 1.1259 & 2.3897 & 0.0802 & 0.1125 & Causal factor \\
\hline$s_{10}$ & 1.1700 & 0.9088 & 0.2612 & 2.0788 & 0.1155 & 0.1409 & Causal factor \\
\hline$s_{11}$ & 1.4166 & 0.7000 & 0.7166 & 2.1166 & 0.0464 & 0.0576 & Causal factor \\
\hline$s_{12}$ & 0.5955 & 0.4444 & 0.1511 & 1.0399 & 0.0464 & 0.0283 & Causal factor \\
\hline$s_{13}$ & 1.3703 & 0.5689 & 0.8014 & 1.9392 & 0.0802 & 0.0913 & Causal factor \\
\hline$s_{14}$ & 0.6237 & 0.7798 & -0.1561 & 1.4035 & 0.0464 & 0.0382 & $\begin{array}{l}\text { Resulting } \\
\text { factor }\end{array}$ \\
\hline$s_{15}$ & 0.6669 & 0.7752 & -0.1083 & 1.4421 & 0.0322 & 0.0273 & $\begin{array}{l}\text { Resulting } \\
\text { factor }\end{array}$ \\
\hline$s_{16}$ & 0.9693 & 1.0635 & -0.0942 & 2.0328 & 0.0464 & 0.0554 & $\begin{array}{l}\text { Resulting } \\
\text { factor }\end{array}$ \\
\hline
\end{tabular}

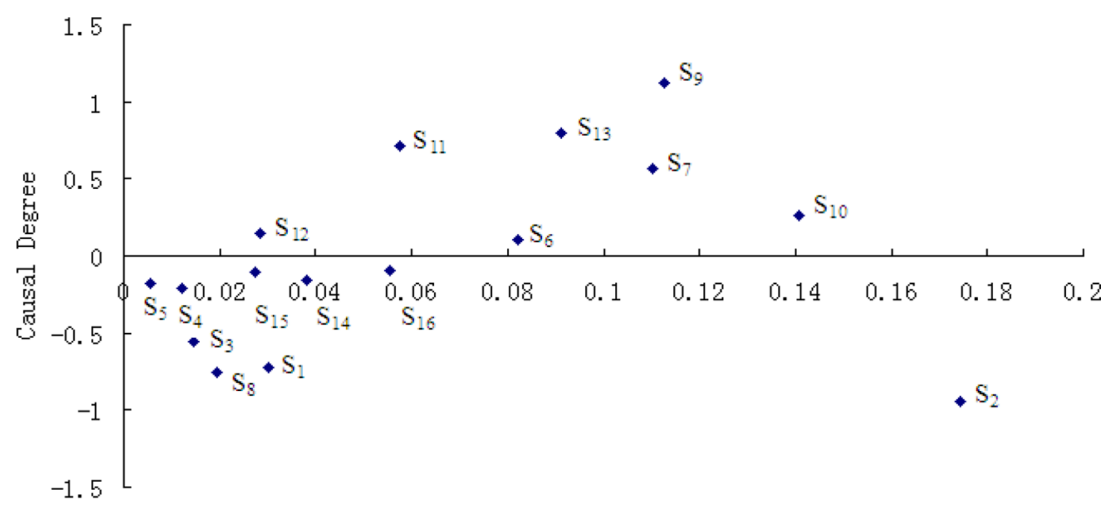

Important Degree

Figure 1: Important degree and causal degree of influencing factors on airline employee's safety integrity. 
4.1 Calculating the global impact matrix $\mathrm{H}$

The comprehensive influence matrix reflects only the mutual influence relationship, and does not consider the influence of the factors on themselves. Therefore, according to eqn (5) the comprehensive influence matrix is processed to form the whole influence matrix.

$$
H=I+T=\left[h_{i j}\right]_{n \times n}
$$

\subsection{Calculating the reachable matrix $\mathrm{K}$}

In ISM, the reachable matrix $\mathrm{K}$ reflects the interaction among factors, and the range of the elements in the matrix is $\{0,1\} \cdot k_{i j}=0(i=1,2, \cdots, n ; j=1,2, \cdots, n)$, meaning that $a_{i}$ and $a_{j}$ do not interact with each other, and $k_{i j}=1$ means that $a_{i}$ and $a_{j}$ do interact with each other. The global influence matrix can not only reflect the influence relationship between factors, but also reflect the degree of influence among factors. Therefore, the reachable matrix can be obtained by setting the influencing degree threshold.

$$
K=\left[\mathrm{k}_{i j}\right]_{n \times n}
$$

Define $k_{i j}=1$, if $\mathrm{h}_{\mathrm{ij}} \geq \lambda(i, j=1,2,3 \ldots n)$

Define $k_{i j}=0$, if $\mathrm{h}_{\mathrm{ij}}<\lambda(i, j=1,2,3 \ldots n)$

According to the value of global influence matrix and the expert opinion, $\lambda=0.1$ was set up to construct the reachable matrix $\mathrm{K}$ of influencing factors on safety integrity.

$$
K=\left|\begin{array}{llllllllllllllll}
1 & 0 & 0 & 0 & 0 & 0 & 0 & 0 & 0 & 0 & 0 & 0 & 0 & 0 & 0 & 0 \\
0 & 1 & 0 & 0 & 0 & 0 & 0 & 0 & 0 & 0 & 0 & 0 & 0 & 0 & 0 & 0 \\
0 & 0 & 1 & 0 & 0 & 0 & 0 & 0 & 0 & 0 & 0 & 0 & 0 & 0 & 0 & 0 \\
0 & 0 & 0 & 1 & 0 & 0 & 0 & 0 & 0 & 0 & 0 & 0 & 0 & 0 & 0 & 0 \\
0 & 0 & 0 & 0 & 1 & 0 & 0 & 0 & 0 & 0 & 0 & 0 & 0 & 0 & 0 & 0 \\
0 & 1 & 0 & 0 & 0 & 1 & 0 & 1 & 0 & 1 & 0 & 0 & 0 & 0 & 0 & 0 \\
0 & 1 & 0 & 0 & 0 & 1 & 1 & 0 & 0 & 1 & 0 & 0 & 1 & 1 & 0 & 1 \\
0 & 0 & 0 & 0 & 0 & 0 & 0 & 1 & 0 & 0 & 0 & 0 & 0 & 0 & 0 & 0 \\
0 & 1 & 0 & 0 & 0 & 1 & 1 & 1 & 1 & 1 & 1 & 1 & 1 & 1 & 1 & 1 \\
0 & 1 & 0 & 0 & 0 & 1 & 0 & 0 & 0 & 1 & 0 & 0 & 0 & 0 & 0 & 1 \\
0 & 1 & 0 & 0 & 0 & 0 & 1 & 0 & 1 & 1 & 1 & 0 & 1 & 1 & 1 & 1 \\
0 & 0 & 0 & 0 & 0 & 0 & 0 & 0 & 0 & 0 & 0 & 1 & 0 & 0 & 0 & 0 \\
1 & 1 & 0 & 0 & 0 & 1 & 1 & 0 & 1 & 1 & 1 & 0 & 1 & 0 & 0 & 1 \\
0 & 0 & 1 & 0 & 0 & 0 & 0 & 0 & 0 & 0 & 0 & 0 & 0 & 1 & 0 & 0 \\
0 & 0 & 0 & 0 & 0 & 0 & 0 & 0 & 0 & 0 & 0 & 0 & 0 & 0 & 1 & 0 \\
0 & 1 & 0 & 0 & 0 & 0 & 0 & 0 & 0 & 1 & 0 & 0 & 0 & 0 & 0 & 1
\end{array}\right|
$$


4.3 Constructing the hierarchical structure model of influencing factors based on reachable set and antecedent set

The reachable set and the preceding set of $s_{i}$ element are defined as $R_{i}$ and $P_{i}$.

$$
\begin{aligned}
& R_{i}=\left\{s_{j}\right\}, s_{j} \in S, k_{i j}=1, i=1,2, \cdots, n \\
& P_{i}=\left\{s_{j}\right\}, s_{j} \in S, k_{j i}=1, i=1,2, \cdots, n
\end{aligned}
$$

If $R_{i}=R_{i} \cap S_{i},(i=1,2, \ldots n)$, the corresponding element $s_{i}$ is the top-level element.

By calculation, $L_{1}=\left\{\begin{array}{llllllll}s_{1} & s_{2} & s_{3} & s_{4} & s_{5} & s_{8} & s_{12} & s_{15}\end{array}\right\}$,

$$
L_{2}=\left\{\begin{array}{llll}
s_{6} & s_{10} & s_{14} & s_{16}
\end{array}\right\}, L_{3}=\left\{\begin{array}{ll}
s_{7} & s_{13}
\end{array}\right\} ; L_{4}=\left\{\begin{array}{ll}
s_{9} & s_{11}
\end{array}\right\} .
$$

The hierarchical structure model of influencing factors on airline employee's safety and integrity is shown in Fig. 2.

\section{RESULTS AND DISCUSSION}

As shown in Table 2, the causal degrees of some factors are greater than zero, and they are causal factors. According to the causal degree from big to small order, they are $s_{9}, s_{13}, s_{11}, s_{7}, s_{10}$ $, s_{12}, s_{6}$. These factors all have a great influence on other factors.

As shown in Table 2, the importance of the 6 factors is the highest, according to the importance of influencing factors in the system. They are $s_{2}, s_{10}, s_{9}, s_{7}, s_{13}, s_{6}$. These six factors have a strong impact on the target. The importance of $s_{4}$ and $s_{5}$ is the least and their influences are small.

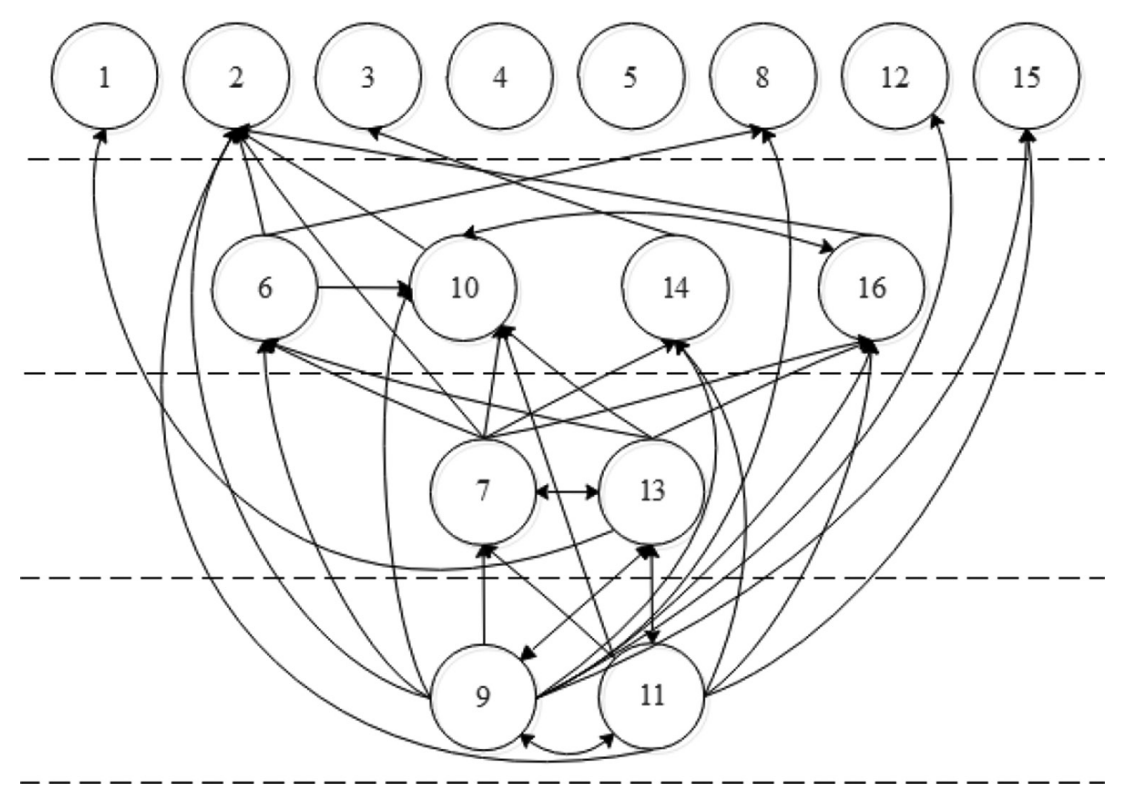

Figure 2: Hierarchical structure of influencing factors on airline employee's safety integrity. 
As shown in Fig. 1, there are 6 factors at the top right of the figure. They are not only causal factors, but also the most important factors. These 6 factors are $s_{6}, s_{7}, s_{9}, s_{10}, s_{11}, s_{13}$. They are the factors that we need to pay much more attention to. Among them, factors of $s_{7} s_{9} s_{11} s_{13}$ are at the bottom of the hierarchical structure model, which means they are the root factors of unsafe integrity behavior. They are the most important factors.

As shown in Fig. 2, the interaction systems of influencing factors can be divided into 4 layers. The first layer is the appearance layer, and the factors include $s_{1}, s_{2}, s_{3}, s_{4}, s_{5}, s_{8}, s_{12}, s_{15}$. The second layer is the middle layer. The third and the fourth layer are the root layer, the factors include $s_{7}, s_{9}, s_{11}, s_{13}$. The root layer affects the appearance layer by the intermediate layer. The factors of appearance layer are the direct causes that affect airline employee's safety integrity. The factors of root layer are the deep causes that affect airline employee's safety integrity.

\section{CONCLUSIONS}

The paper first defined the connotation of safety integrity, and used Field Theory to carry out cases analysis, and identified the main factors that affect the safety integrity of airline employees. By using DEMATEL-G1 and DEMATEL-ISM, the relationships between factors were analyzed quantitatively, and the internal effect path of influencing factors was established. The main conclusions were as follows:

1. The main factors affecting the safety integrity of airline employees include the following factors: "individual professional knowledge and skills", "individual awareness of safety integrity", "individual physical condition", "individual psychological state", "facilities of air traffic control department and airport", "social and industrial currents", "incentive and penalty system of safety integrity", "communication and coordination among airlines, airport and air traffic control department", "supervision of government and company", "related education, propaganda and safety cultural atmosphere", "stability and efficiency of the organization", "standardization of guidance documentation", "emphasis and example of leaders on safety integrity", "management of organizational resource", "safety input", "establishment of the company management system and division of job responsibilities".

2. Of all factors, the following factors are crucial: "social and industrial currents", "incentive and penalty system of safety integrity", "supervision of government and company", "related education, propaganda and safety cultural atmosphere", "stability and efficiency of the organization", "emphasis and example of leaders on safety integrity". They are not only the causal factors, but also of high importance. They are of great significance for improving the safety integrity of employees. Paying attention to the improvement of these factors can improve the safety integrity of employees effectively.

3. The whole influencing mechanism can be divided into 4 layers. The factors of appearance layer includes "individual professional knowledge and skills", "individual awareness of safety integrity", "individual physical condition", "individual psychological state", "facilities of air traffic control department and airport", "communication and coordination among airlines, airport and air traffic control department", "standardization of guidance documentation", "safety input". They are the direct causes that affect airline employee's safety integrity. The factors of root layer include "incentive and penalty system of safety integrity", "supervision of government and company", "stability and efficiency of the organization", "emphasis and example of leaders on safety integrity". The root layer 
influences the appearance layer by influencing the intermediate layer. They are the deep causes that affect airline employee's safety integrity. And "individual psychological state", "facilities of air traffic control department and airport" are relatively independent in hierarchical structure graph and have no connection with other factors.

There are many factors affecting safety integrity. In addition to the psychological and physiological characteristics, the external, natural and social environment, etc., there may be ethnic differences, political unrest and so on. The factors discussed in this paper were obtained through the analysis of 86 typical cases of violating safety integrity. As ethnic differences, political unrest and other factors were not reflected in cases analysis, these factors were not the focus of the study. In addition, the objectivity and scientificity of experts' scores have great influence on the results of the study. This study mainly considered the influence of different professional backgrounds, cultural backgrounds and work experiences of different experts. The influence of such factors as different ethnic and social backgrounds will be paid attention to in subsequent research.

The conclusions of this paper mainly reflect the factors that affect the safety integrity of airline employees in the last ten years and the mechanism of the factors. With the rapid development of civil aviation demand, the contradiction between supply and demand of civil aviation industry is remarkable. The new factors affecting the safety integrity of airline employees will appear continuously, so in future research it is necessary to analyze the impact of these factors on safety integrity in time.

\section{ACKNOWLEDGEMENT}

The authors gratefully express their appreciation to three anonymous reviewers for their insightful comments to this manuscript and thankfully acknowledge the financial support to the project "airlines safety integrity evaluation and system" by the Civil Aviation Safety Ability Construction Fund (Grant number ASSA0005-2014).

\section{REFERENCES}

[1] Special report: fleet watch 2017- a review of commercial aircraft orders and deliveries for 2016. Flight Global, 28 Feb 2017, available at: http://dashboard.flightglobal.com

[2] Cunningham, M.R. \& Ash, P., The structure of honesty: factor analysis of the Reid report. Journal of Business and Psychology, 3(1), pp. 54-66, 1988. https://doi.org/10.1007/bf01016748

[3] Ones ,D.S. \& Viswesvaran, C., Gender, age and race differences on overt integrity tests: analyses across four large-scale applicant data sets. Psychology, 83(1), pp. 35-42, 1998. https://doi.org/10.1037//0021-9010.83.1.35

[4] Marcus, B., Höft, S. \& Riediger, M., Integrity tests and the five-factor model of personality: a review and empirical test of two alternative positions. International Journal of Selection and Assessment, 14(2), pp. 113-130, 2006. https://doi.org/10.1111/j.1468-2389.2006.00338.x

[5] Byle, K.A. \& Holtgraves, T.M., Integrity testing, personality, and design: interpreting the personnel reaction blank. Journal of Business \& Psychology, 22(4), pp. 287-295, 2008. https://doi.org/10.1007/s10869-008-9059-z

[6] Mcfarland, L.A. \& Ryan, A.M., Variance in faking across non cognitive measures. Journal of Applied Psychology, 85(5), pp. 812-821, 2000.

https://doi.org/10.1037//0021-9010.85.5.812 
[7] Alliger, G.M. \& Dwight, S.A., A meta-analytic investigation of the susceptibility of integrity tests to faking and coaching. Educational and Psychological Measurement, 60(1), pp. 59-72, 2000. https://doi.org/10.1177/00131640021970367

[8] Farisi, M.I., Academic dishonesty in distance higher education: challenges and models for moral education in the digital era. Turkish Online Journal of Distance Education, 14(4), pp. 176-195, 2013.

[9] Kisamore, J.L., Stone, T.H. \& Jawahar, I.M., Academic integrity: the relationship between individual and situational factors on misconduct contemplations. Journal of Business Ethics, 75(4), pp. 381-394, 2007. https://doi.org/10.1007/s10551-006-9260-9

[10] Oxford English Dictionary, Oxford University Press, 2002.

[11] Dudzinski, D.M., Integrity: principled coherence, virtue, or both? The Journal of Value Inquiry, 38(3), pp. 299-313, 2004. https://doi.org/10.1007/s10790-005-3337-z

[12] Vinnem, J.E., Offshore Risk Assessment vol 1: Principles, Modelling and Applications of QRA Studies, Springer-Verlag: London and New York, pp. 89, 2010.

[13] Palanski, M.E. \& Yammarino, F.J., Integrity and leadership: clearing the conceptual confusion. European Management Journal, 25(3), pp. 171-184, 2007. https://doi.org/10.1016/j.emj.2007.04.006

[14] Cheng, D.Q. \& Gu, F., Coal mine safety integrity evaluation model based on Bayesian networks. Journal of Safety and Environment, 11(4), pp. 230-233, 2011.

[15] Ji, P.P. \& Li, X.C., Safety integrity system construction of coal mining enterprises employees. Coal Mine Safety, 10, pp. 122-124, 2010.

[16] Cheng, G.Y., Weng, Y.F., Lu, Y.F. \& Zhang, X.C., Discussion on enterprise safety production and integrity system. Proceedings of 2010 (Shenyang) International Colloquium on Safety Science and Technology, pp. 13-16, 2010.

[17] Worlds' Civil Aviation Accident Investigation, Civil Aviation Administration of China, Office of Aviation Safety, 2017, available at: http://safety.caac.gov.cn (Accessed 15 March 2017)

[18] Lewin, K., A dynamic theory of personality: selected papers. Journal of Nervous \& Mental Disease, 84(5), pp. 612-613, 1936. https://doi.org/10.1097/00005053-193611000-00051

[19] Sims, R.R. \& Brinkman J., Leaders as moral role models: the case of John Gutfreund at Salomon brothers. Journal of Business Ethics, 35(4), pp. 327-339, 2002. https://doi.org/10.1023/a:1013826126058

[20] Trevino, L.K., Brown, M. \& Laura, P., A qualitative investigation of perceived executive ethical leadership: perceptions from inside and outside the executive suite. Human Relations, 56(1), pp. 5-37, 2003. https://doi.org/10.1177/0018726703056001448

[21] White, D.W. \& Lean, E., The impact of perceived leader integrity on subordinates in a work team environment. Journal of Business Ethics, 81(4), pp. 765-778, 2008. https://doi.org/10.1007/s10551-007-9546-6

[22] Grover, S.L., Lying, deceit, and subterfuge: a model of dishonesty in the workplace. Organization Science, 4(3), pp. 478-495, 1993.

https://doi.org/10.1287/orsc.4.3.478 
[23] Ross, W.T. \& Robertson, D.C., Lying: the impact of decision context. Business Ethics Quarterly, 10(2), pp. 409-440, 2000. https://doi.org/10.2307/3857884

[24] Lewicki, R.J., Poland, T., Minton, J.W. \& Sheppard, B.H., Dishonesty as deviance: a typology of workplace dishonesty and contributing factors. Research on Negotiation in Organizations, 6, pp. 53-86. 1997.

[25] Scott, E.D., Plane truth: a qualitative study of employee dishonesty in the airline industry. Journal of Business Ethics, 42(4), pp. 321-337, 2003. https://doi.org/10.1023/a:1022579909460

[26] Fontela, E. \& Gabus, A., DEMATEL: Progress achieved. Futures, 6(4), pp. 361-363, 1974. https://doi.org/10.1016/0016-3287(74)90086-x

[27] Guo, Y.J., Comprehensive Evaluation Theory and Method, Science Press: Beijing, 2002.

[28] Wang, X.J. \& GUO Y.J., Analyzing the consistency of comparison matrix based on G1 method. Chinese Journal of Management Science, 14(3), pp. 65-68, 2006.

[29] Warfield, J., Binary matrices in system modeling. IEEE Transactions on Systems, Man, and Cybernetics, SMC-3(5), pp. 441-448, 1973. https://doi.org/10.1109/tsmc.1973.4309270

[30] Zhou, D.Q. \& Zhang, L., Establishing hierarchy structure in complex systems based on the integration of DEMATEL and ISM. Journal of Management Sciences in China, 11(2), pp. 20-26, 2008. 